\title{
Ecological fingerprinting of ecosystem succession: Estimating secondary tropical dry forest structure and diversity using imaging spectroscopy
}

\author{
M. Kalacska ${ }^{\text {a }}$, G.A. Sanchez-Azofeifa ${ }^{a, *}$, B. Rivard ${ }^{\text {a }}$, T. Caelli ${ }^{\text {, }}$, \\ H. Peter White ${ }^{\mathrm{d}}$, J.C. Calvo-Alvarado ${ }^{\mathrm{c}}$ \\ ${ }^{a}$ Earth and Atmospheric Sciences Department, University of Alberta, Edmonton Alberta, Canada T6G $2 E 3$ \\ ${ }^{\mathrm{b}}$ National Information and Communications Technology (ICT) Australia, The Australian National Univeristy, Canberra ACT 0200, Australia \\ ${ }^{\mathrm{c}}$ Costa Rican Technological Institute, Cartago, Costa Rica \\ d Canada Center for Remote Sensing, Natural Resources Canada, Ottawa, Canada K1A 0Y7
}

Received 23 April 2006; received in revised form 3 November 2006; accepted 4 November 2006

\begin{abstract}
We evaluated the use of EO-1 Hyperion hyperspectral satellite imagery for mapping structure and floristic diversity in a Neotropical tropical dry forest as a way of assessing a region's ecological fingerprint. Analysis of satellite imagery provides a means to spatially appraise the dynamics of the structure and diversity of the forest. We derived optimal models for mapping canopy height, live aboveground biomass, Shannon diversity, basal area and the Holdridge Complexity Index from a dry season image. None of the evaluated models adequately estimated stem or species density. Due to the dynamic nature of the leaf phenology we found that for the application of remote sensing in Neotropical dry forests, the spectro-temporal domain (changes in the spectral signatures over time-season) must be taken into account when choosing imagery. The analyses and results presented here provide a means for rapid spatial assessment of structure and diversity characteristics from the microscale site level to an entire region.
\end{abstract}

(C) 2006 Elsevier Inc. All rights reserved.

Keywords: Tropical dry forest; Holdridge Complexity Index; Structure; Biomass; Hyperspectral remote sensing; Costa Rica; Wavelet decomposition; Hyperion; Neural network

\section{Introduction}

In the tropics, with increasing threats of forest degradation, biodiversity loss and the loss of environmental services, there has been an escalating need for in-depth studies into forest dynamics and biophysical characteristics in order to support sustainable resource development and achieve environmental protection goals (Daily et al., 1997; Sanchez-Azofeifa et al., 2003 , 2005). Forty-seven percent of the global forest cover is in the tropics (FAO, 2001) and of that, $75 \%$ is considered Dry or Moist Forest (Holdridge, 1967 as cited by Murphy \& Lugo, 1986). However, those two ecosystems are also among the most frequently disturbed (anthropogenically) and among the least

\footnotetext{
* Corresponding author. Tel.: +1 780492 1822; fax: +1 7804922030.

E-mail address: arturo.sanchez@ualberta.ca (G.A. Sanchez-Azofeifa).
}

protected (Janzen, 1986; Mooney et al., 1995; Quesada \& Stoner, 2004).

Tropical forest monitoring by means of optical and infrared remote sensing has become both increasingly popular and feasible with the advent of satellite sensors such as Landsat 7 ETM+, ASTER, IKONOS, Quickbird, Hyperion and ALI. Monitoring efforts have generally consisted of large scale land use/ land cover change (Sanchez-Azofeifa et al., 2001; Townshend et al., 1991) and the estimation of broad forest biophysical characteristics (Fournier et al., 2003; Running et al., 1986; Tuner et al., 1999; Thenkabail et al., 2004; White et al., 2001 among others) which are integral for understanding physiological, ecological and biogeochemical processes (Asner et al., 2002).

Forest characteristics extracted from remotely sensed data are important for global atmosphere-biosphere models (i.e. water, energy and carbon dioxide flux) (Schlerf et al., 2005), the 
creation of environmental policies and conservation areas (Pfaff et al., 2000; Pfaff and Sanchez-Azofeifa, 2004) and secondary forest characterization (Arroyo-Mora et al., 2005). Recently, there has been considerable interest in estimating detailed forest biophysical characteristics such as leaf area index (LAI), tree height, biomass and crown diameter from remotely sensed data (Asner et al., 2002; Atzberger, 2004; Clark et al., 2004; Greenberg et al., 2005a,b; Kalacska et al., 2004a, 2005b; Schlerf et al., 2005; White et al., 2002, among many others). Canopy demography is then often further employed to improve harvest plans (Asner et al., 2002) and assess canopy damage and recovery after selective logging (Asner et al., 2004). Nevertheless, the majority of the studies linking remote sensing and ecosystem succession in the tropics have been from the Amazon (Brondizio et al., 1996; Foody et al., 1996; Mausel et al., 1993; Steininger, 1996, 2000 among others; see Castro et al., 2003 for a comprehensive review).

A second area of recent interest has been the estimation of biodiversity from remotely sensed data. In general there are two approaches: direct remote sensing of species assemblages and communities or an indirect estimation through the use of other environmental variables (Turner et al., 2003). Examples of the direct approach include species composition and land cover discrimination. The indirect approach comprises broad areas such as primary productivity, chlorophyll, climate (e.g. soil moisture, phenology) and habitat structure (e.g. topography, vertical canopy structure) (Kerr \& Deguise, 2004; Turner et al., 2003). Some of the most important uses of the indirect approach are biomass estimation, drought prediction and mapping land cover dynamics and land cover heterogeneity (Gould, 2000; Foody, 2003) all of which have important impacts on biodiversity. A similar indirect measure of biodiversity is the classification (in descending order of scale) of ecoregions, ecomosaics and ecotopes (Nagendra \& Gadgil, 1999a). In this classification, each ecoregion has a unique community of species and environmental conditions. Ecomosaics are finer types within an ecoregion and ecotopes are characterized by an even finer spatial detail colonized by a unique species composition of a particular group such as flowering plants. At each of the levels, the classes are distinguishable by remote sensing and are significantly different from each other in composition with respect to the different entities at the next lower level (Nagendra \& Gadgil, 1999a,b). Measures of vegetation biodiversity (i.e. indices of species richness and evenness) have been linked to remotely sensed data most often through the classification of the forest based on the similarity of tree species or similarity in landscape elements (Foody \& Cutler, 2003; Menon \& Bawa, 1997; Nagendra \& Gadgil, 1999a,b; Nagendra, 2001). At the landscape scale the results are employed for conservation science and management decisions. However, in many studies, the remotely sensed data has been underutilized by the calculation of vegetation indices and the use of surrogates (i.e. biomass, land cover type and heterogeneity) for species richness estimations (Foody \& Cutler, 2003). An important drawback to such studies is the non-transferability of results from one area to another, even within ecosystem types (Foody et al., 2003).
In this study we use the concept of an "ecological fingerprint" as a "spatial description of forest structure and floristic diversity" that is analogous to a snapshot in time. Secondary forests are becoming more prominent in the landscape in many Neotropical countries, and therefore, are the future of forest management and monitoring. We incorporate their inherent heterogeneity into the ecological fingerprint and develop models that can monitor the dynamics of their changes over time. Until the acceptance that secondary forests could act as positive carbon sinks (Brown \& Lugo, 1990), they were generally regarded as inferior to old-growth. Furthermore, the characterization of these forests has generally been through "age since abandonment" chronosequences (Lucas et al., 2000; Ruiz et al., 2005). However, as Arroyo-Mora et al. (2005) have shown, successional stages quantified by forest structure, are a more accurate categorization especially for the Neotropical tropical dry forest and for studies incorporating remotely sensed data specifically. Hence the creation of models to examine individual structural and diversity elements (e.g. canopy height, basal area, etc.) that quantify successional stage will produce "snapshots" of their regeneration state and a method for monitoring over time.

Here, we directly examine forest structure and biodiversity (through the Shannon diversity index) estimation from satellite imagery. We address the inference and mapping of Neotropical dry forest biophysical characteristics (i.e. structure), biomass and species richness directly from hyperspectral remote sensing imagery acquired over three seasons: wet, transition and dry. We explore techniques such as spectral vegetation indices and the application of wavelet decomposition - a common practice in the signal processing community — with regression models for inference. We also reconstruct the wavelet decomposition as a way to locate the most important spectral regions for mapping the biophysical characteristics. Each aforementioned technique is described in the following methods section. Through these methods the potential for monitoring forest structure and diversity is shown with potentials for monitoring over time; applications for which range from testing theoretical regeneration hypotheses to assessing habitat quality.

\section{Methods}

\subsection{Study area}

The study site is located in the Santa Rosa National Park (Guanacaste Province), a World Heritage Site, in north-western Costa Rica $\left(10^{\circ} 48^{\prime} 53^{\prime \prime} \mathrm{N}, 85^{\circ} 36^{\prime} 5^{\prime \prime} 4 \mathrm{~W}\right)$. Over time, the national park has come to be known as the Santa Rosa sector of a larger conservation area called the Área de Conservación Guanacaste (ACG). This area receives an average of $1500 \mathrm{~mm}$ of precipitation per year with a 6 month dry season (December to May) where the majority of the vegetation is deciduous. We refer to this area as a seasonally dry Neotropical forest based on the definition from Sanchez-Azofeifa et al. (2005): an area with a vegetation type dominated by deciduous trees, with a mean temperature $>25{ }^{\circ} \mathrm{C}$, a total annual precipitation range of $700-$ $2000 \mathrm{~mm}$ and three or more dry months (precipitation 
$<100 \mathrm{~mm})$. The vegetation in Santa Rosa is a mosaic of secondary forest in various successional stages with interspersed pastures (Janzen, 1988a,b, 2000; Kalacska et al., 2004b). The land use history, intensity of past uses and discrete anthropogenic fire history of Santa Rosa is highly varied (Kalacska et al., 2004b). Some of the more common past land uses for this area were pasture, dryland rice, timber extraction, agriculture and banana plantation (Kalacska et al., 2004b). The majority of the park is located in relatively flat uplands ( $\sim 250 \mathrm{~m}$ a.s.1.). Towards the south end of the park canyons with steep slopes descend to sea level ending in a mangrove ecosystem. The structure of the regenerating vegetation has been greatly affected by the various land uses in the area dating back to the colonial times but with greater changes over the last 50 years. Taking this into account we categorize the forest by its horizontal and vertical structures when sampling the vegetation and describing the successional stages. We refer to three successional stages for the vegetation (Table 1): early, intermediate and late as described by Kalacska et al. (2004b, 2005a,b) and Arroyo-Mora et al. (2005). The early stage is composed of many small trees, shrubs and open areas and in general has a heterogeneous canopy with an average basal area of $11.7 \pm 5.4 \mathrm{~m}^{2} / \mathrm{ha}$. The intermediate stage is composed generally of deciduous trees with lianas forming a substantial component of the canopy (average basal area of $21.4 \pm 6.8 \mathrm{~m}^{2} / \mathrm{ha}$ and the late stage is composed of two canopy strata including dominant canopy trees, shade tolerant species and overlapping crowns; average basal area has been shown to be $30.1 \pm 6.5 \mathrm{~m}^{2}$ / ha (Kalacska et al., 2004b). At the time of images acquisition (December 2002-March 2003) the intermediate stage comprised $40 \%$ of the study site, the late stage $27 \%$, the early stage $19 \%$ and pasture lands $12 \%$ and the other $2 \%$ roads and buildings that belong to the research station (Arroyo-Mora et al., 2005)

\subsection{Field data}

Structure and floristic composition was measured in twentysix $20 \times 50 \mathrm{~m}$ ( $0.1 \mathrm{ha}$ ) plots (10 early, 10 intermediate, 6 late) for woody stems (trees and lianas) with a $\mathrm{DBH} \geq 5 \mathrm{~cm}$ during two field seasons in December 2002 and February 2003 (Kalacska et al., 2004b) (Fig. 1). The 0.1 ha plot size was chosen for the
Holdridge Complexity Index (Holdridge, 1967) as described below. The location of each plot was recorded with a Trimble GeoExplorer III GPS unit, spatial accuracy of the GPS is estimated at $\pm 5-8 \mathrm{~m}$. At the time of site selection the heterogeneity of the forest was examined such that the plots were located within forest areas that have not only similar structure but also a similar reflectance as expressed by the Normalized Difference Vegetation Index (Kalacska et al., 2004b). Analysis of Ripley's $K$ function (Freeman \& Ford, 2002; Ripley, 1976) indicates a random distribution of the sites at scales of $0-5000 \mathrm{~m}$ indicating that at those scales the locations of the plots are randomly oriented in space and are not spatially auto-correlated (Kalacska et al., 2004b). Total above ground live biomass was calculated from the following allometric equation from Brown (1997):

$$
\mathrm{ATB}=\exp \{-1.996+2.32(\ln D)\}
$$

where biomass is expressed in kilograms of dry mass and $D$ is DBH in centimeters. From the structural variables we calculated the Holdridge Complexity Index (HCI) from Holdridge (1967):

$\mathrm{HCI}=\frac{H G D S}{10000}$

where $H$ is canopy height $(\mathrm{m}), G$ is basal area $\left(\mathrm{m}^{2} / \mathrm{ha}\right), D$ is stem density (No./0.1 ha) and $S$ is species density (No./0.1 ha). Being a quantitative index, HCI provides a more objective measure of overall forest physiognomy than verbal descriptions or single structural variables. To estimate floristic diversity we use the Shannon diversity index $\left(H^{\prime}\right)$ (Magurran, 2004):

$H^{\prime}=-\sum p_{i} \ln p_{i}$

where $p_{i}$ is the proportion of individuals from the $i$ th species. Plant-area-index (PAI) was estimated optically with the LAI2000 in sixteen of the plots (7 early, 6 intermediate, 3 late) (Kalacska et al., 2005a,b). PAI was subsequently calibrated using dry season measurements of wood-area-index (from hemispherical photographs) and leaf litter traps to calculate leafarea-index (LAI) (Kalacska et al., 2005a). Though not included in this analysis, minimum and maximum LAI for the stages is

Table 1

Summary of the biophysical and diversity characteristics per successional stage

\begin{tabular}{|c|c|c|c|c|c|c|c|c|c|}
\hline Stage & Height & Basal area & Stem density & Species density & Shannon diversity & Biomass & $\mathrm{HCI}$ & $\begin{array}{l}\text { Mean LAI } \\
\text { (dry season) }\end{array}$ & $\begin{array}{l}\text { Mean LAI } \\
\text { (wet season) }\end{array}$ \\
\hline Early & $\begin{array}{l}7.5 \pm 2.2 \\
(4.6-11.5)\end{array}$ & $\begin{array}{l}11.7 \pm 5.4 \\
(3-19)\end{array}$ & $\begin{array}{l}112 \pm 64 \\
(21-195)\end{array}$ & $\begin{array}{l}15 \pm 7 \\
(5-28)\end{array}$ & $\begin{array}{l}1.77 \pm 0.56 \\
(0.57-2.65)\end{array}$ & $\begin{array}{l}5.6 \pm 3.3 \\
(1.1-10.9)\end{array}$ & $\begin{array}{l}28.0 \pm 36.0 \\
(0.5-121.1)\end{array}$ & $0.3 \pm 0.7$ & $3.8 \pm 2.6$ \\
\hline Intermediate & $\begin{array}{l}10.3 \pm 3.4 \\
(6.7-15.8)\end{array}$ & $\begin{array}{l}21.4 \pm 6.8 \\
(13-32)\end{array}$ & $\begin{array}{l}130 \pm 35 \\
(51-177)\end{array}$ & $\begin{array}{l}29 \pm 5 \\
(23-35)\end{array}$ & $\begin{array}{l}2.88 \pm 0.36 \\
(2.14-3.36)\end{array}$ & $\begin{array}{l}10.9 \pm 4.6 \\
(5.8-17.0)\end{array}$ & $\begin{array}{l}68.8 \pm 57.7 \\
(27.4-129.8)\end{array}$ & $0.3 \pm 0.6$ & $3.7 \pm 1.2$ \\
\hline Late & $\begin{array}{l}15.0 \pm 2.2 \\
(12.7-17.5)\end{array}$ & $\begin{array}{l}30.1 \pm 6.5 \\
(21-39)\end{array}$ & $\begin{array}{l}107 \pm 42 \\
(88-209)\end{array}$ & $\begin{array}{l}29 \pm 7 \\
(22-40)\end{array}$ & $\begin{array}{l}2.75 \pm 0.56 \\
(2.22-3.39)\end{array}$ & $\begin{array}{l}16.0 \pm 4.3 \\
(10.5-23.4)\end{array}$ & $\begin{array}{l}159.0 \pm 57.7 \\
(110.2-235.8)\end{array}$ & $1.5 \pm 0.9$ & $11.3 \pm 4.9$ \\
\hline
\end{tabular}

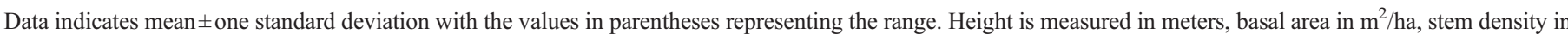

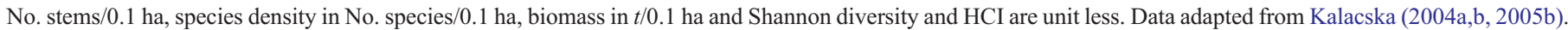

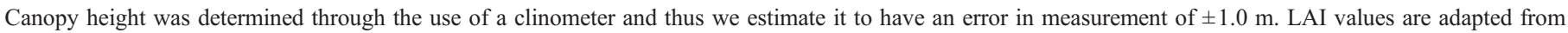
Kalacska et al. (2005a,b) and represent calibrated LAI values. 
included for completeness in the summary of the structural and floristic characteristics in Table 1.

\subsubsection{Image processing-pre-processing}

The satellite images used in this study were three atmospherically corrected Hyperion scenes (220 bands, $30 \mathrm{~m}$ spatial resolution) acquired March 2002, December 2002 and January 2003 as shown in Fig. 2 with the leaf phenological cycle. The Hyperion imagery pre-processing and atmospheric correction followed the methodology presented by White et al. (2004) using the Imaging Spectrometer Data Analysis Systems (ISDAS), an image processing tool developed at the Canada Centre for Remote Sensing (Staenz et al., 1998). Their methodology consists of geometrically registering the shortwave infrared with the visible-near infrared data. Subsequently, stripes and pixel dropouts are removed and noise is reduced using techniques developed (Sun et al., submitted for publication). Next, keystone and smile detection software is applied to characterize distortions (Neville et al., 2003) and finally a MODTRAN based atmospheric correction procedure is used to convert radiance to reflectance (Khurshid et al., 2006).

The pixel values for each of the twenty-six sites were extracted from each image in a $3 \times 3$ pixel window around the centre of each plot. Because the orientation of the plots does not coincide with the orientation of the pixels and because single pixels cannot be precisely registered to a GPS locations

a)

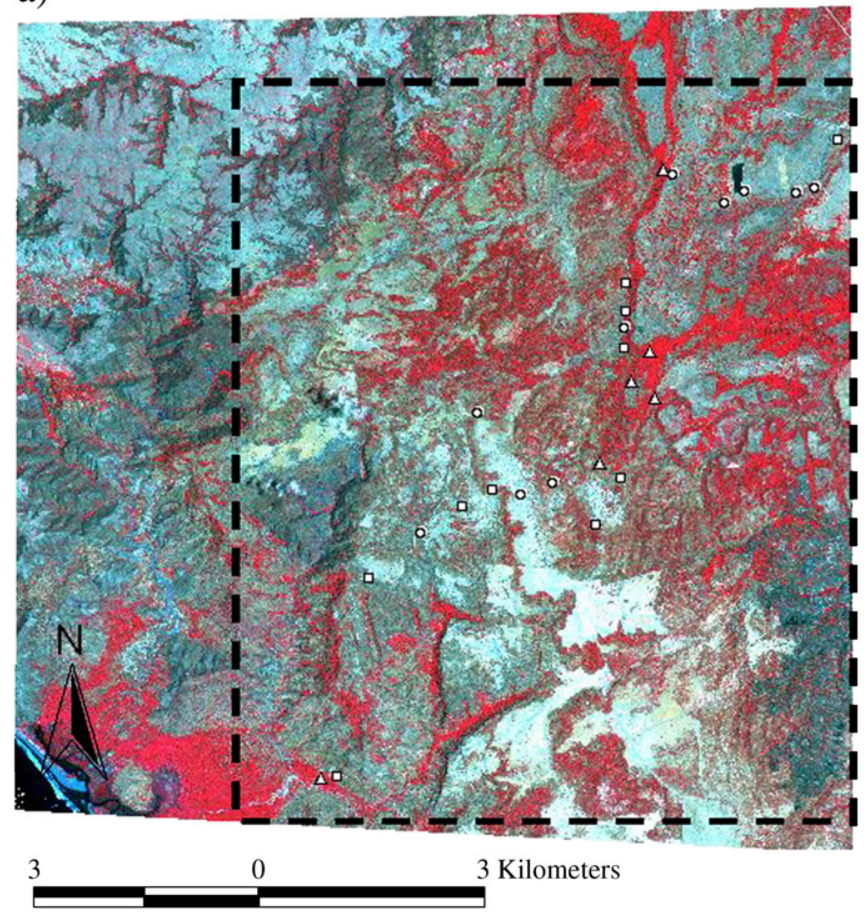

Fig. 1. a) IKONOS high spatial resolution image of Santa Rosa National Park with the location of the field sites. Circles represent early sites, squares represent intermediate sites, triangles represent late sites. Dashed line represents area covered by the Hyperion imagery; b) photograph of the successional stages in the dry and wet seasons A: representative early stage, B: extreme early stage, $\mathrm{C}$ : representative intermediate stage, D: representative late stage. b)

Dry Season

Wet Season

A
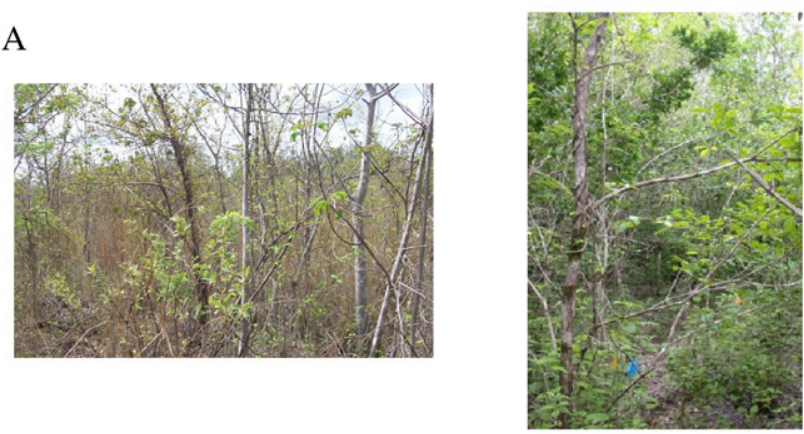

B
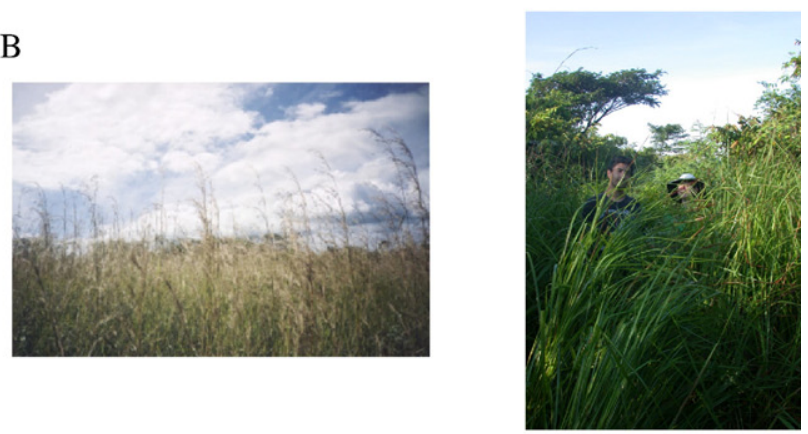

C
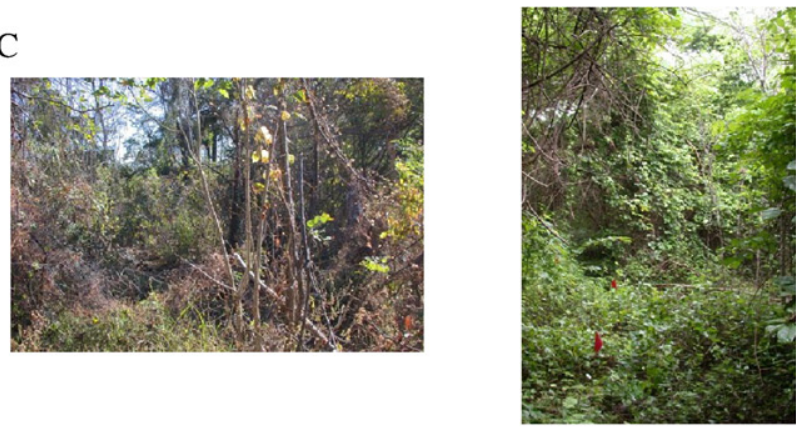

D
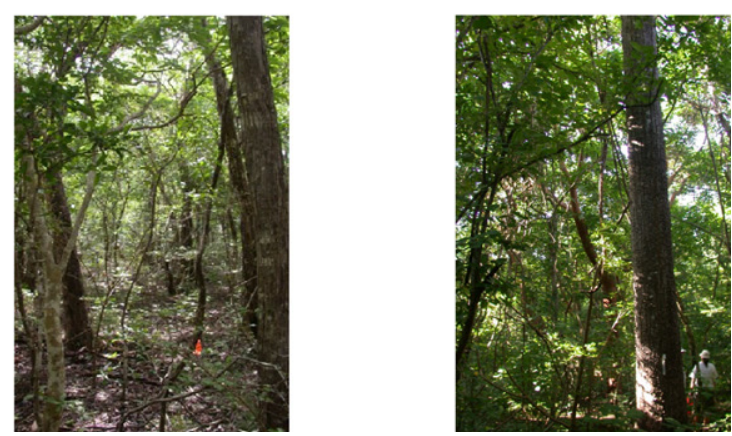

Fig. 1 (continued).

we chose to use a $3 \times 3$ pixel window. At the time of site selection the heterogeneity of the forest was examined to locate the plots within forest areas that have uniform structure and reflectance as expressed by the Normalized Difference Vegetation Index (Kalacska et al., 2004b; Arroyo-Mora et al., 2005). The bands with a low signal-to-noise ratio $(<430 \mathrm{~nm}$ and $>2400 \mathrm{~nm}$ ) and within water absorption features (centered 
around $1400 \mathrm{~nm}$ and $1900 \mathrm{~nm}$ ) were removed resulting in a total of 153 bands for the analysis. The following analyses were applied separately for each of the three images.

\subsubsection{Image processing - calculation of spectral metrics}

Spectral vegetation indices - We examined six narrowband spectral vegetations (SVIs) namely the Normalized Difference Vegetation Index - $\mathrm{ND}_{705}$ - (Sims \& Gamon, 2002), Canopy Normalized Difference Vegetation Index $-\mathrm{ND}_{\text {canopy }}-$ (Sims \& Gamon, 2003), Single Ratio - $\mathrm{SR}_{705}$ - (Sims \& Gamon, 2002), Canopy Single Ratio - SR canopy - (Sims \& Gamon, 2002), Modified Single Ratio - MSR - (Chen, 1996), and Canopy Structure Index - CSI - (Sims \& Gamon, 2003) (Table 2). These indices were chosen because they are both common in the literature and have shown to be sensitive to canopy characteristics in other ecosystems by exploiting the variability of features such as the chlorophyll absorption well.

Wavelet transform - Wavelet transform is a time-scale signal analysis technique that may reveal features of a signal (e.g. reflectance spectrum) such as trends or discontinuities that other techniques may miss (Misiti et al., 1996). A wavelet is a waveform of limited duration and, accordingly breaks up a signal into shifted and scaled versions of the original waveform (i.e. mother wavelet) corresponding to increasing degrees of detail or higher frequencies. The benefit of the wavelet transform is that it occurs in both temporal and spectral domains and so retaining positional information while also encoding detail or spectral information. With discrete wavelet transforms, signals are analyzed over a set of discrete dyadic scales (i.e. one that increments by the power of two $\left(2^{j}\right.$, $j=1,2,3 \ldots . . n))$. The set of wavelet basis functions $\left\{\psi_{a, b}(\lambda)\right\}$ are

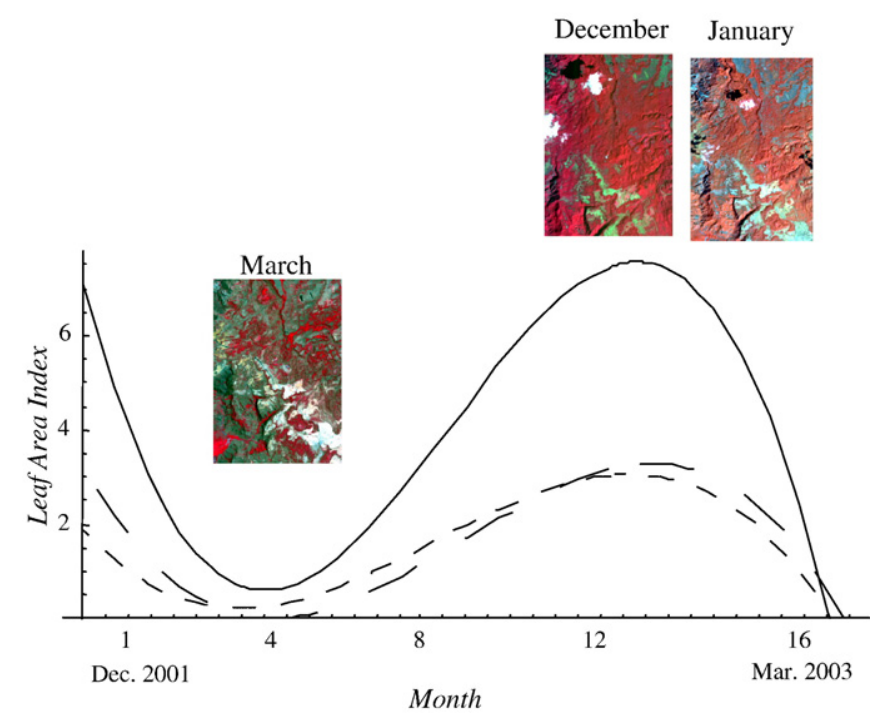

Fig. 2. Hyperion images for Santa Rosa National Park (March, December and January) superimposed above the leaf phenological cycles for the early (dashed), intermediate (long dashes) and late (solid) stages. Reprinted from Tree Physiology, 25, Kalacska, Calvo-Alvarado, Sanchez-Azofeifa G.A. Calibration and assessment of seasonal changes in leaf area of a tropical dry forest in different stages of succession, 733-744 Copyright (2004), with permission from Heron Publishing.
Table 2

Spectral vegetation indices used in this study

\begin{tabular}{ll}
\hline Spectral vegetation index & Formula \\
\hline $\mathrm{ND}_{\text {canopy }}$ & $\left(R_{800}-R_{680}\right) /\left(R_{800}+R_{680}\right)$ \\
$\mathrm{ND}_{705}$ & $\left(R_{750}-R_{705}\right) /\left(R_{750}+R_{705}\right)$ \\
$\mathrm{SR}_{\text {canopy }}$ & $R_{800} / R_{680}$ \\
$\mathrm{SR}$ & $R_{750} / R_{705}$ \\
$\mathrm{MSR}$ & $\frac{R_{800}}{R_{680}-1}$ \\
& $\frac{\sqrt{\frac{R_{800}}{R_{680}}+1}}{2 \mathrm{SSR}-\mathrm{SSR}^{2}+\mathrm{SWI}^{2}}$ \\
$\mathrm{CSI}$ & $\mathrm{where:}$ \\
& $\mathrm{SSR}=\frac{\frac{R_{800}}{R_{680}}-1}{\left(\frac{R_{800}}{R_{680}}-1\right)_{\max }}$ \\
& $\mathrm{SWI}=\frac{\frac{R_{900}}{R_{1180}}-1}{\left(\frac{R_{900}}{R_{1180}}-1\right)_{\max }}$ \\
\hline
\end{tabular}

calculated for spectral data by shifting and scaling the mother wavelet, $\Psi(\lambda)$, across the data (Bruce et al., 2002).

$\left\{\psi_{a, b}(\lambda)=\frac{1}{\sqrt{a}} \psi\left(\frac{\lambda-b}{a}\right)\right.$

with a zero average condition $\int_{-\infty}^{+\infty} \psi(\lambda) \partial \lambda=0$ where $a>0$ and $b$ are real numbers with " $a$ " being the scaling factor of the basis function and " $b$ " the shifting/translational variable along the function's range (Bruce et al., 2002). The discrete wavelet transform basis functions can be defined as:

$\psi_{j, k}(\lambda)=2^{\frac{-j}{2}} \psi\left(2^{-j} \lambda-k\right)$

where $j$ is the $j$ th decomposition level and $k$ is the $k$ th wavelet coefficient at the $j$ th level. The wavelet coefficients can be obtained by:

$W_{j, k}=\left\{f(\lambda), \psi_{j, k}(\lambda)\right\}$

where the scales are $a=2,4,8 \ldots .2^{j}, \ldots . .2^{p}$ (Bruce et al., 2002).

At each level of the decomposition, the result of the high and low pass filters is a set of approximation $\left(\mathrm{cA}_{j}\right)$ (from low pass filter) and detail $\left(\mathrm{cD}_{j}\right)$ (from high pass filter) coefficients ( $\mathrm{Li}$ et al., 2001; Mallat, 1989; Misiti et al., 1996) (Fig. 3). The theoretical maximum number of decomposition levels is $p=\log _{2}(N)$ where $N$ is the length of the initial input signal (Bruce et al., 2002) (e.g. number of spectral bands).

We conducted a discrete wavelet transform of the Hyperion spectra using a mother wavelet from the Daubechies family (db3). While the choice of the mother wavelet is generally arbitrary, the $\mathrm{db} 3$ wavelet was chosen because of the results from $\mathrm{Pu}$ and Gong (2004) who after comparing several mother wavelets, found the $\mathrm{db} 3$ to be the best for the estimation of canopy openness and leaf area index. The multilevel decomposition to 7 levels was implemented in Matlab 


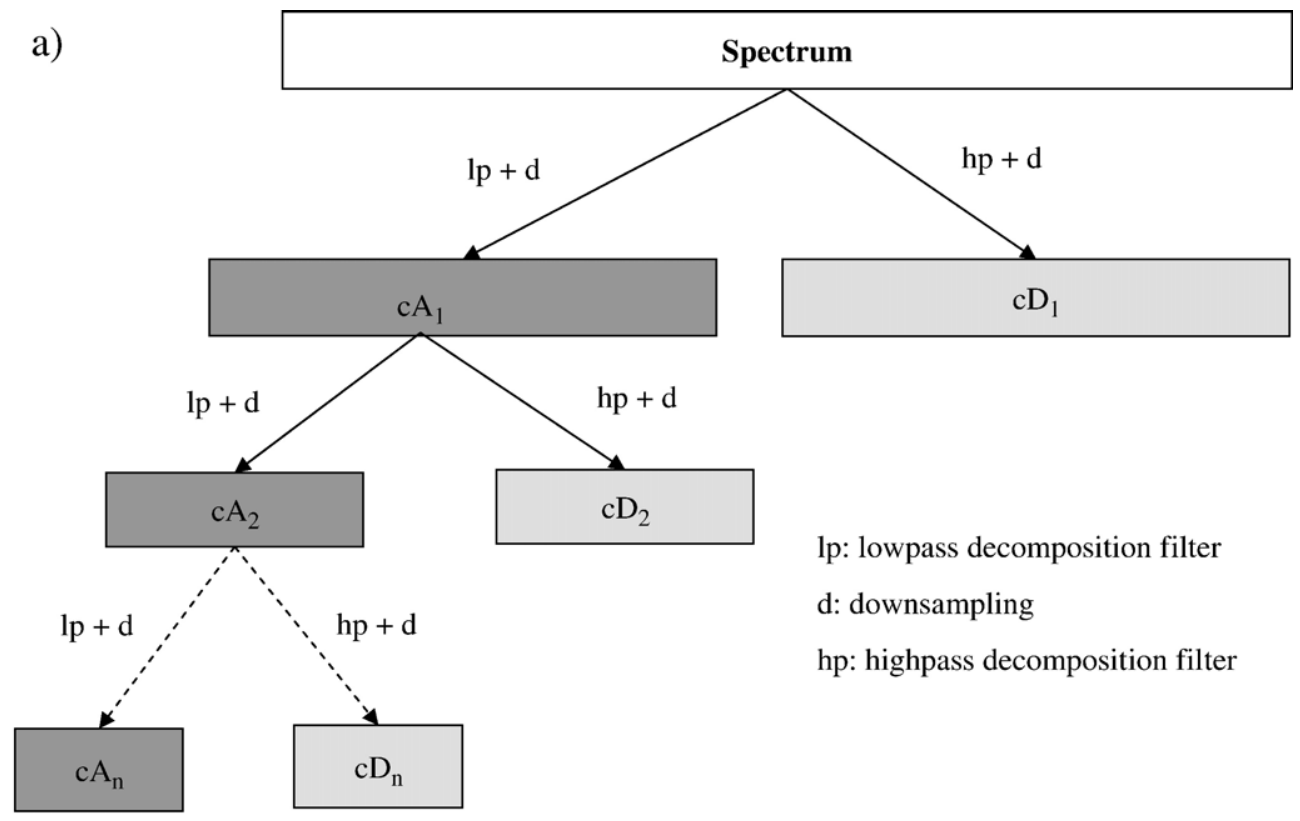

b)

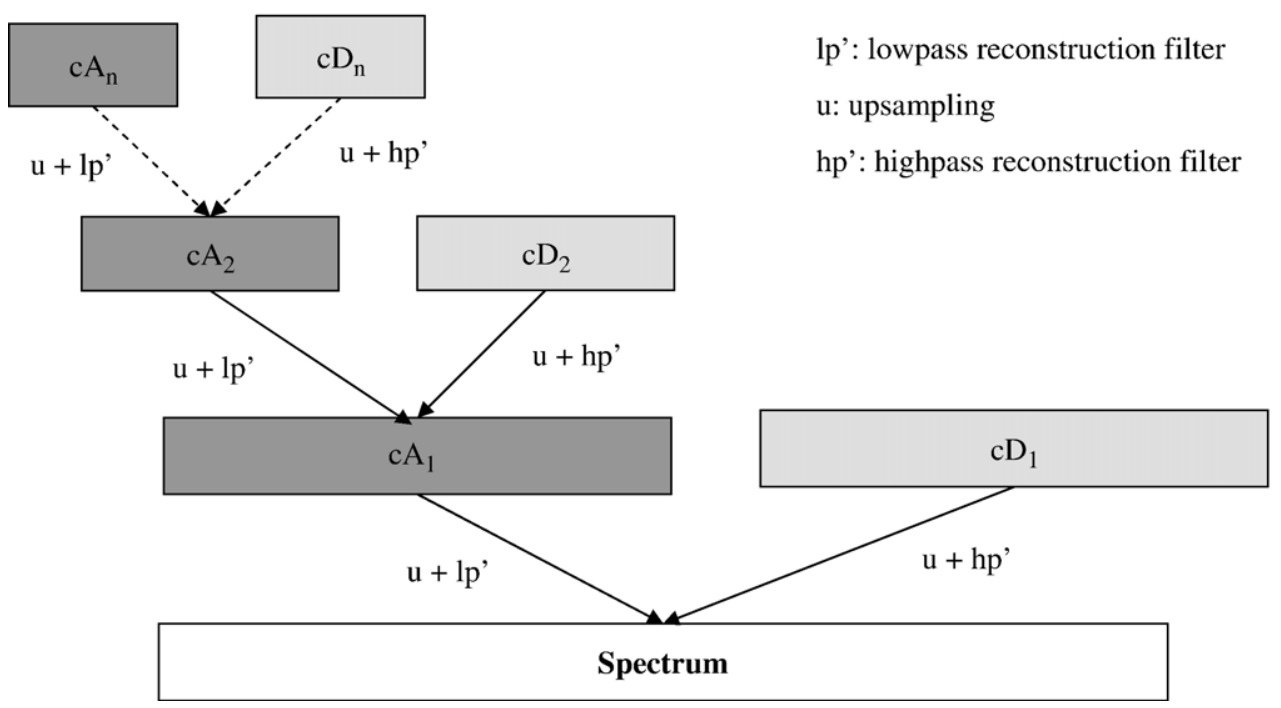

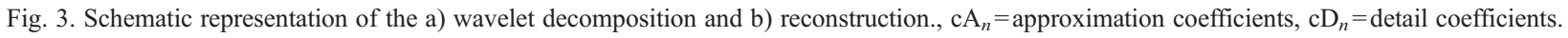

v.6.5 resulting in 7 detail coefficients $\left(\mathrm{cD}_{1-7}\right)$ and the largest approximation coefficient $\left(\mathrm{cA}_{7}\right)$ with a combined length of 182 elements.

Energy feature vector - Our final spectral metric approach consisted of calculating the scalar energy feature vector of the detail and approximation coefficients from the wavelet decomposition described above using the following formula (Bruce et al., 1999; Li et al., 2001; Pu \& Gong, 2004):

$$
F_{j}=\sqrt{\frac{1}{K} \sum_{K=1}^{K} W_{j k}^{2}}
$$

where $K$ is the number of coefficients at level $j, W_{j k}$ is the $k$ th coefficient at level $j$. The length of the vector is $j+1$ (i.e. the detail coefficients and the approximation coefficient) where $j$ is the maximum number of decomposition levels. With this method, the dimensions of the data have been reduced to 8 .

\subsubsection{Image processing - model building/validation}

Following the calculation of the spectral metrics, various regression models were employed with the reduced/transformed data to infer the forest characteristics from the images (Fig. 4). For the SVIs the regression models had one predictor variable (i.e. one regression model for each SVI). Depending on the relationship of each index with the forest characteristics, both 


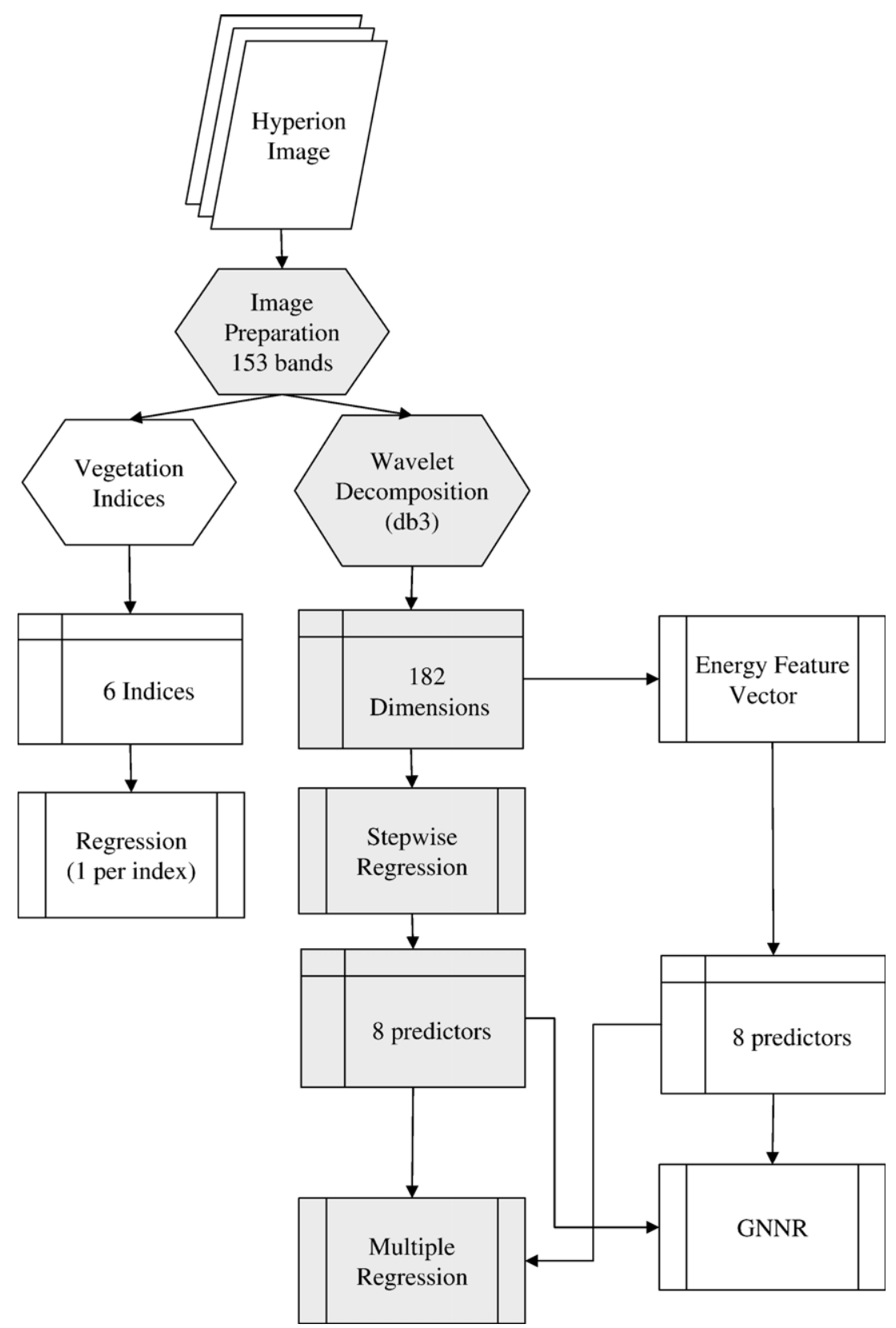

Fig. 4. Image processing methodologies for estimating forest structure, biomass and species richness from the March Hyperion image. Optimal method is highlighted in grey. GNNR $=$ Generalized Neural Network Regression.

linear and non-linear models were constructed to find the best forest characteristic prediction model for a given SVI.

For the wavelet transforms, a stepwise linear regression was first used to reduce the 182 elements to the optimal predictor elements (Fig. 4). For each forest characteristic, the optimal model from the stepwise regression consisted of a linear model with 8 elements (i.e. 8 predictor variables for each forest characteristic). For the energy feature vector, the regression models for the forest characteristics also included 8 predictor variables (i.e. the 8 elements from the calculation of the energy feature vector for the detail coefficients of the 7 decomposition levels and the approximation coefficients from the final level) (Fig. 4).
Subsequently, because the wavelet transform and the energy feature techniques both have multiple predictor variables (i.e. 8 predictor variables for each forest characteristic) we compared a multiple regression and a generalized regression neural network to estimate the forest characteristics from the 8 predictor variables (Fig. 4). Generalized regression neural networks consist of a radial basis layer and a special linear layer and are often used to estimate functions (Wasserman, 1993).

To test the effectiveness of the final models we used a crossvalidation (Isaaks \& Srivastava, 1989) to assess the validity of the models. This "leave-one-out" validation technique was used due to the limited number of data points (i.e. 26 sites total). Each withheld data point was sequentially estimated by the models to 
produce an overall estimation of the fit. The model with the best fit following validation was then run on a pixel by pixel basis over the image (using Matlab v.6.5) to create maps of the biophysical characteristics and floristic diversity.

\subsubsection{Wavelet decomposition}

Specifically for the wavelet decomposition, the wavelength regions corresponding to the elements chosen by the stepwise regression were obtained by conducting an inverse discrete wavelet transform (Fig. 3b). The wavelet decomposition approach may be "reversed" to reconstruct each decomposition level (starting from $\mathrm{cA}_{7}$ and $\mathrm{cD}_{7}$ ) by inverting the decomposition step first through upsampling (i.e. addition of zeros between each element in the "odd" locations of the vector) and subsequently convolving the resulting array with reconstruction filters for the given wavelet ( $\mathrm{db} 3$ in this case). The general reconstruction formula is (de Carvalho et al., 2004; Mallat, 1989):

$a_{j, k}=\sum_{l}\left[h(k-2 l) d_{j+1, l}+g(k-2 l)\right] d_{j-1, l}$

for all $j, k$, where $h$ and $g$ are the high pass and low pass reconstruction filters, $j$ and $k$ are the level and location in the array (e.g. $a_{2,3}$ is third element in the approximation coefficients at the second level), $d$ are the detail coefficients and $l$ is the length of the vector.

\section{Results}

For most of the 26 sites, the most distinct reflectance spectrum in terms of its shape is the one from the early stage in March (dry season) (Fig. 5). For nearly all early stage sites a higher reflectance in the near infrared is observed in comparison to the other two time periods (December and January). For the intermediate and late stages, the most distinct difference is a less prominent green peak and red absorption in the dry season image (most dramatic in the early stage) (Fig. 5).

For all three images, none of the vegetation indices had the strongest relationship with the biophysical variables. The values for the coefficient of determination were between 0.27 and 0.56 for the SVIs. The only exception was the relationship between the SVIs $\mathrm{ND}_{\text {canopy }}, \mathrm{ND}_{705}, \mathrm{MSR}, \mathrm{SR}_{\text {canopy }}, \mathrm{SR}$ and canopy height that had an $R^{2}$ consistently between 0.62 and 0.66 for all images.

The results from the regression models (both multiple regression and generalized neural network) with the wavelet energy feature vectors were also similar to the SVIs. The models for all of the biophysical characteristics for December and January ranged from $R^{2}=0.20$ for species density (January) to $R^{2}=0.68$ for canopy height (January). For the March image the models were weaker with a range from $R^{2}=0.05$ (stem density, species density, Shannon diversity, $\mathrm{HCI}$ ) to $R^{2}=0.45$ for biomass.

When specific elements from the approximation and detail coefficients were selected from the wavelet decomposition using the stepwise regression the models for all variables a)

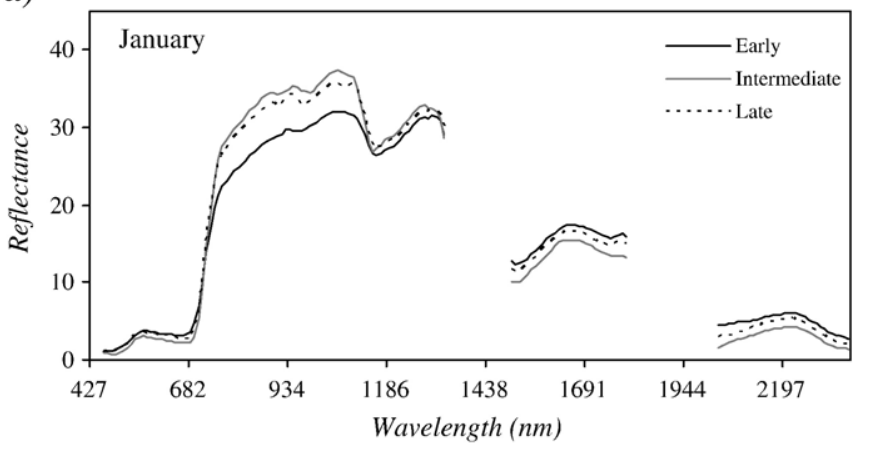

b)

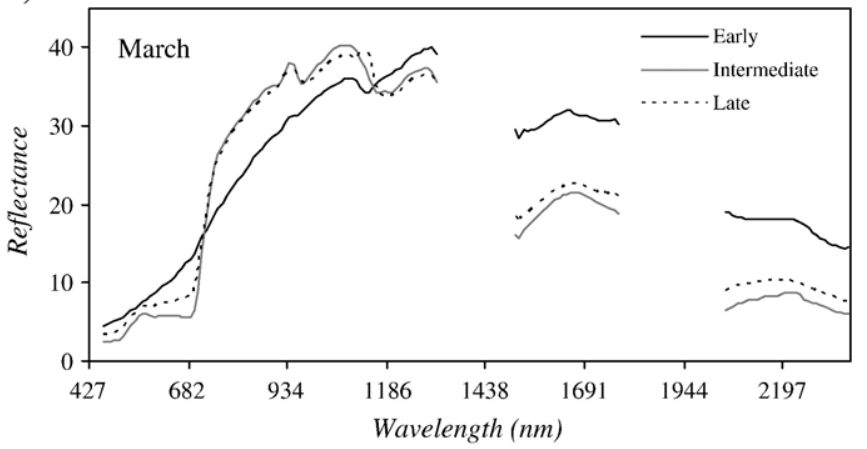

c)

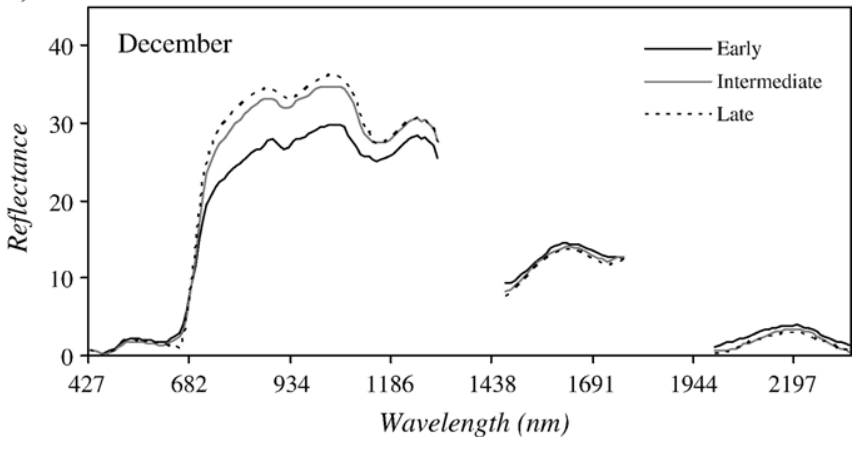

Fig. 5. Mean spectra for representative plots for the early, intermediate and late stages from the a) January (transition season), b) March (dry season), c) December (wet season).

improved for each image for both the final multiple regression or generalized neural network regression (i.e. models for each variable had an $R^{2}>0.80$ ). When considering whether to construct the maps using regression from the multiple regression or the generalized neural network regression, we took the strong variability in forest characteristics among sites (Table 1) into consideration because the generalized neural network regression tends to be sensitive to outliers. For the sites that were close to the mean value of the biophysical characteristics, the neural network regression had the lowest error in the cross-validation. However, for the sites that were outliers from the mean the error from the cross-validation on the neural network regression was very large indicating that model had overfit the data and would thus not be useful in predicting variables over a broader area in the landscape (Boddy \& Morris, 1999; Russell \& Norvig, 2003). For the multiple regression the error from the cross-validation remained fairly constant for all 
Table 3

Results from the best fit validation models for estimating the forest characteristics: wavelet decomposition followed by a stepwise regression

\begin{tabular}{lllc}
\hline Forest characteristic & Image & Adj. $R^{2}$ & RMSE \\
\hline Biomass (kg/0.1 ha) & March & 0.85 & 2109.7 \\
Height (m) & March & 0.92 & 1.1 \\
Basal area (m²/ha) & March & 0.88 & 3.2 \\
Shannon species richness & March & 0.84 & 0.26 \\
Holdridge Complexity Index & March & 0.63 & 33.3 \\
Species density (No./0.1 ha) & March & 0.47 & 6.6 \\
Stem density (No./0.1 ha) & March & 0.20 & 43.5 \\
\hline
\end{tabular}

Units are respective to each characteristic.

sites regardless of whether they were close to the mean, thus less sensitive to outliers This is an important consideration because as can be seen in Table 1, there is a wide range of values with several outliers for all biophysical characteristics.
The overall best model for biomass, Shannon species richness, canopy height, Holdridge Complexity Index and basal area were the multiple regression using the elements from the wavelet transform approximation and detail coefficients selected by the stepwise procedure from the March image (Table 3, Fig. 4). There was no suitable model following validation for stem or species densities. However, species density has a relatively strong relationship with Shannon species richness $\left(R^{2}=0.79\right)$ for our study area and could subsequently be mapped from Shannon species richness $\left(S=9.96 \times H^{\prime}\right)$. Unfortunately, no such relationship is present for stem density and thus it cannot be reliably mapped using the methods presented here for this study site.

In summary, the most accurate and robust model for estimating the biophysical characteristics and diversity was the wavelet transform, followed by a stepwise regression from the March (dry season) image to select the optimal elements for a)

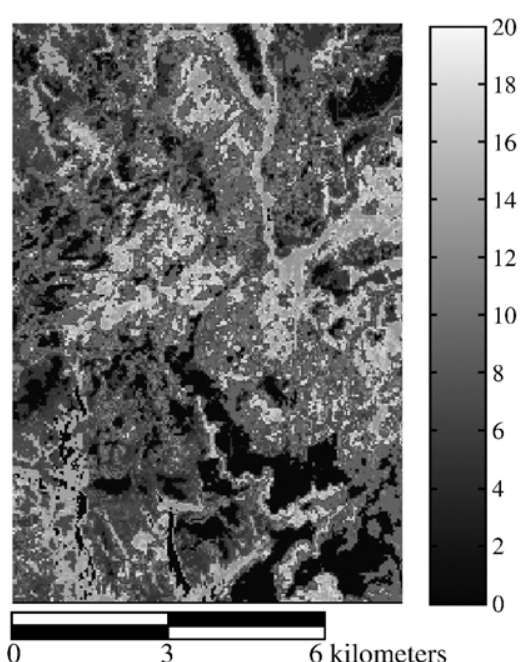

d)

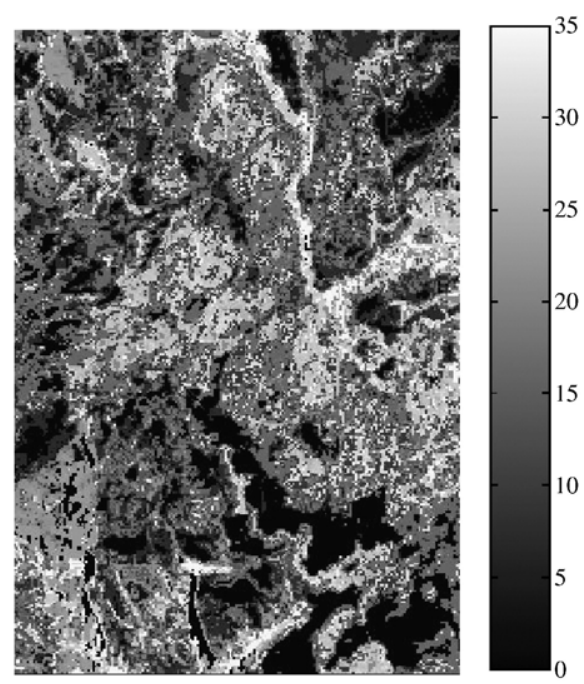

b)

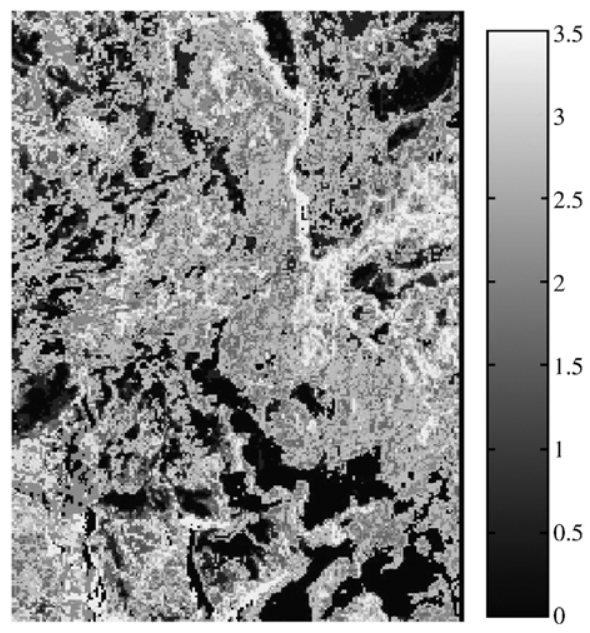

c)

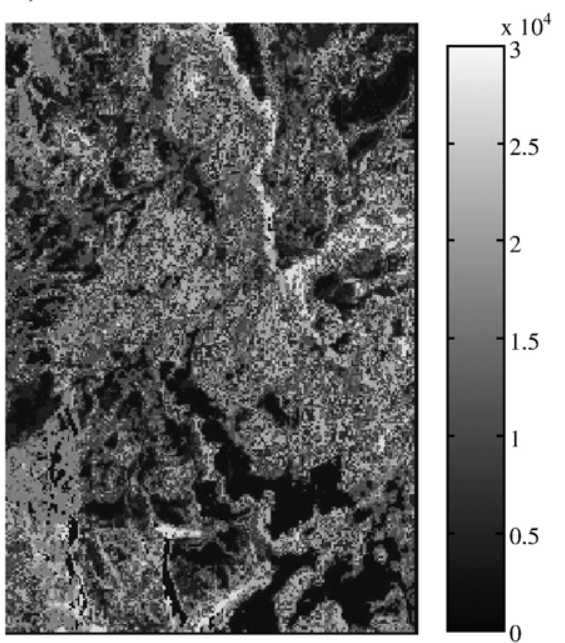

e)

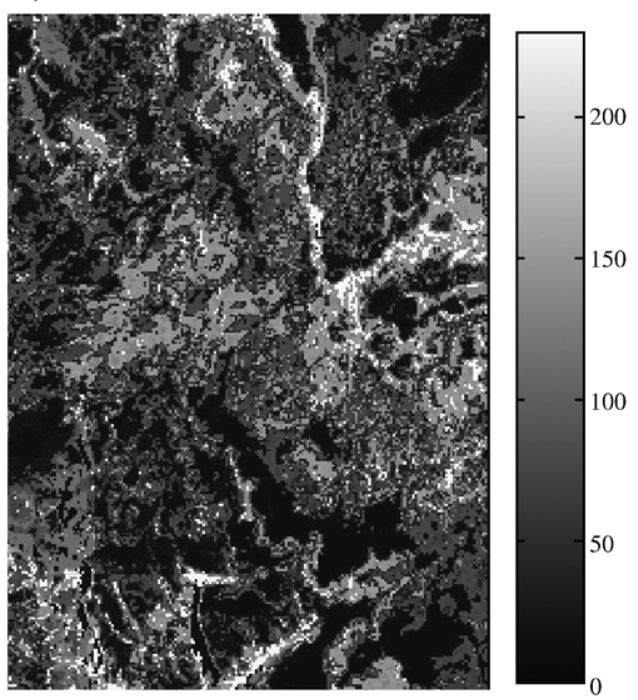

Fig. 6. Resulting forest structure, biomass and species richness maps estimated from the March Hyperion image. a) canopy height (m), b) Shannon species richness, c) biomass $(\mathrm{kg} / 0.1 \mathrm{ha}) \mathrm{d})$ basal area $\left(\mathrm{m}^{2} \mathrm{ha}\right)$ e) Holdridge complexity index. 
inclusion in a multiple regression model. Subsequently as illustrated in Fig. 4, we mapped canopy height, biomass, basal area, Shannon diversity and HCI (Fig. 6). The majority of the features chosen from the wavelet decomposition were from $\mathrm{cD}_{1}$ and $\mathrm{cD}_{2}$. Upon closer examination of the wavelengths that were associated with the elements chosen for each stage, it was found that for biomass the wavelengths were primarily in the visible $(498,621,682 \mathrm{~nm})$ and near infrared regions $(743,865 \mathrm{~nm})$ of the spectrum with only three from the shortwave infrared (1227, 1589, $2237 \mathrm{~nm})$. For canopy height, HCI and basal area, all wavelengths were from the near infrared and shortwave infrared $(743-2257 \mathrm{~nm})$. Finally, for Shannon species richness all wavelengths were from the shortwave infrared $(1206-2237 \mathrm{~nm})$ except for one from the visible $(621 \mathrm{~nm})$.

\section{Discussion}

Our results highlight the importance of considering the season of image acquisition ("spectro-temporal domain") when mapping variables that define ecological succession for the tropical dry forest. The differences in horizontal canopy structure (i.e. LAI and canopy openness) between the stages are the most pronounced during the dry season. These differences in structure translate into different levels of contribution from green leaves, leaf litter, non-photosynthetic elements such as bark, exposed soil and dry grass to the spectral response for each stage. Utilizing the methodology presented here, the dynamics — the changes over time (e.g. 5 year change) of the structure and composition of the forest over a larger area can be monitored from snapshots of variables that comprise the forest's structure such as 5 year changes in basal area or biomass. While this methodology only provides an index of species diversity and does not identify individual species given the coarse spatial resolution of our data, results from Clark et al. (2005), Castro-Esau et al. (2006) and Zhang et al. (2006) show that certain individual species from the tropics can be identified spectrally using in-situ spectrometry and high spatial resolution hyperspectral imagery. Including such identifications (by means of finer spatial resolution hyperspectral data) and monitoring species turnover through time would add another dimension to the concept of the ecological fingerprint. The importance of season is also emphasized by Castro-Esau et al. (2006) who illustrate the changes to the spectral reflectance of individual tropical species over seasons. Similarly, for a temperate forest located in the Pacific Northwest of the United States, Roberts et al. (2004) show a trend between stand attributes (such as age, composition and structure) and hyperspectral canopy reflectance along with the changes through forest succession. Roberts et al. (2004) also reaffirm the utility of remote sensing to illustrate the spatial patterns of stands in various stages of succession.

The relationships between the structure, diversity and the imagery were the most accurate when the spectra were decomposed by means of a wavelet transform. This decomposition highlighted subtle spectral features that other techniques such as the SVIs missed. The strongest relationships of the SVIs with canopy height can be somewhat expected because the SVIs exploit chlorophyll absorption features, thus being sensitive to chlorophyll, which is related to LAI. LAI is in turn related to successional stage and canopy height (Kalacska et al., 2005a).

It is also clear from the results that there is much redundant and confounding information in the spectra; the use of select components of the wavelet decomposition chosen by means of a stepwise regression filtered the spectra in order to use only the most significant features. This type of "feature selection" on the product of the wavelet decomposition allowed us to utilize only the most meaningful features of the reflectance spectra and provides an insight into the areas of the spectrum that are the most useful for each canopy characteristics as discussed below. Feature selection has been an important aspect in the analysis of hyperspectral data (Castro-Esau et al., 2004; Clark et al., 2005; De Backer et al., 2005; Huang \& He, 2005); here we emphasize its importance in combination with wavelet analysis to extract subtle spectral features (Bruce et al., 1999, 2002; Li et al., 2001; Mallat, 1989; Misiti et al., 1996).

Our findings tend to agree with others such as Lee et al. (2004) and Thenkabail et al. (2004) that the large number of narrow bands of hyperspectral data is an advantage for the estimation of canopy characteristics. By tracing the elements chosen from the wavelet decomposition back to the original wavelengths, it can be seen that all canopy characteristics share similarities in the wavelength regions utilized (such as the shortwave infrared), except for biomass which had important spectral regions in the visible, near infrared and shortwave infrared. In addition, for species richness the shortwave infrared was also heavily favored with the exception of one wavelength from the visible. In contrast, for canopy height, basal area and $\mathrm{HCI}$ none of the wavelengths were from the visible range.

The early stage, which is highly variable in its canopy structure, has a dynamic understory through the seasons (Fig. 1b). In the wet season the small $(\mathrm{DBH}<5 \mathrm{~cm})$ treelets, shrubs and herbs along with grasses (as in pastures) form a thick understory confounding the spectral signature in the open areas and filling the canopy gaps of the early and intermediate stages which begins to resemble that of a mature forest canopy (Fig. 5). In the dry season however, the stages of forest succession are readily separable due primarily to differences in canopy openness (Arroyo-Mora et al., 2005). Kalacska et al. (2004b) found that the majority of the structural variables are distinct for the successional stages in the study area. And thus the reason for the strongest relationships with spectra from the March image is that in a dry season image the various stages of forest regeneration are clearly highlighted in the spectral response (ArroyoMora et al., 2005) and the confusion from green herbaceous understory vegetation is minimized. As illustrated in Fig. 2, the timing of this image corresponds to minimal LAI. It also corresponds to the point in the leaf phenological cycle where the woody component of the canopy has the greatest contribution to reflectance (Kalacska et al., 2005a). At the canopy level, Asner (1998) found that dry herbaceous vegetation significantly alters the spectral response of sparse/open canopies (such as the early stage). Asner (1998) also illustrates a large variability in the reflectance spectra of non-photosynthetic vegetation such as leaf litter and bark with the variability attributed to residual water and species specific differences in carbon and nitrogen for 
the leaf litter and moisture and carbon contents for the bark. Both the litter and bark have smaller water features in the near and shortwave infrared and thus other features characteristic of organic compounds that are usually masked by the water absorption become visible (Asner, 1998; Jacquemoud et al., 1996; Lacaze \& Joffre, 1994; Wessman et al., 1988). Soil, exposed in the canopy gaps also plays an important role in altering the spectral response (Stoner \& Baumgardner, 1981; van der Meer, 1999).

Kalacska et al. (2004b) inventoried 159 woody species in the plots used in this study, with several species being found in either only the early or late stages. The shape of the spectra from the dry season (Fig. 5b) for the early stage approximates the shape of the spectral response of leaf litter and bark illustrated by Asner (1998). As shown in the photographs in Fig. 1b, in the dry season, there is a substantial contribution of leaf litter, dry grasses and exposed bark to the reflectance spectra with the exception of the late stage where green leaves also contribute to the canopy reflectance (Figs. 1b 2 and 5b). The spectral response from Fig. $5 \mathrm{~b}$ is therefore, presumably the result of both the differences in canopy structure and the optical properties of the non-photosynthetic components of the various species that comprise the canopy and are exposed in the dry season. In canopies with a low LAI (such as dry season image) increased photon interactions with the non-photosynthetic components, litter and the soil significantly alter the spectral response (Asner et al., 1998; Asner,1998). In the wet season (i.e. December) when herbaceous understory is a large contributor to the spectral response, our results (Figs. 1b and 5c) also coincide with Asner (1998) who found differences in the reflectance for green leaves between woody and herbaceous species (across seven biomes) with the grasses having a higher reflectance in the visible and a lower reflectance in the near-infrared (but no difference in the shortwave infrared) due to the large variation in leaf nitrogen, carbon and water content amongst woody and herbaceous species. The differences in carbon and nitrogen contents were attributed not only to the range of species sampled, but also to the influence of different soil nutrient content, nitrogen fixers and non-nitrogen fixers and the difference in water content due to several factors such as leaf mesophyll structure, plant physiology and stress (Asner, 1998). Similar differences in reflectance due to various forms of stress, adaptation to solar irradiation (Merzlyak \& Chivkunova, 2000; Peñuelas \& Filella, 1998) or leaf senescence (Gitelson et al., 2001) among others have also been shown. This is an important consideration for the use of wet and transition season imagery in the Neotropical tropical dry forest where the herbaceous understory and the grasses form a major contribution to the spectral response of early and intermediate stages.

The main changes in canopy spectral response attributed to differences in the leaf area index (LAI) (i.e. increased canopy biomass - horizontal and vertical canopy structure) were found to be stronger water absorption features in the near infrared, changes in the red edge, and in the shortwave infrared (Asner, 1998; Ross, 1981). These findings coincide with the differences in mean spectral response between the stages (Fig. 5), especially in the dry season and the importance of the near and shortwave infrared bands for height, basal area and HCI (canopy structure attributes). These differences may be related to the differences in the leaf area index and exposed wood-area-index from the dry and wet seasons respectively among the stages (Kalacska et al., 2005b).

Asner (1998) concluded that at the canopy level, leaf optical properties due to the pigment contents are not an important factor at the canopy level, unless LAI was high where multiple scattering among the leaves enhances biochemical features (e.g. wet season imagery). In addition, differences in canopy leaf angle are significant contributors to the spectral response in the visible region around $550 \mathrm{~nm}$, the red edge and the shortwave infrared. From our results of the most significant wavelength regions, biomass was equally related to the visible, near infrared and shortwave infrared. Based on the results found by Asner (1998) we attribute the difference in canopy openness (Kalacska et al., 2005b) and structure (Table 1) as the most important factor in predicting biomass. Low canopy LAI such as in the early stage (lowest biomass) exposes woody material, leaf litter and soil with minimal to no contribution from green leaves, thus accounting for the importance of the shortwave and near infrared regions. The intermediate stage has an increased contribution of woody material, dry leaves with minimal soil and minimal green leaves while the late stage has a fairly substantial green leaf contribution to the spectral response potentially accounting for the importance of the visible region of the spectrum. The reliance of height, basal area and the Holdridge Complexity Index (all canopy structure attributes) on the near infrared and shortwave infrared tends to indicate that these variables are mostly influenced by canopy water content (i.e. importance of band around $1200 \mathrm{~nm}$ ) and the relative contribution of the exposed non-photosynthetic components of the canopy by the different stages. For the Neotropical dry forest in Santa Rosa N.P. Kalacska et al. (2005a) show that because of the nature of the canopy and the increased number of lianas the intermediate successional stage has a woody-area-index more than double that of the early and late stages. Finally the Shannon species richness estimator with all bands from the shortwave infrared except for one from the visible also tends to indicate sensitivity to the variation in contribution from the nonphotosynthetic components of the canopy and canopy water content as well as being influenced by the green leaf contribution from the late stage.

The results from the vegetation indices are consistent with what was found by Schlerf et al. (2005) using both broadband and narrow band SVIs to estimate stem biomass, volume and LAI in a temperate environment. The strength of the relationships are also similar to the strength of the best correlations reported by Tuomisto et al. (2003) who linked understory floristic patterns to Landsat imagery from the Ecuadorian Amazon. Our lack of an adequate model for estimating stem density is contrary to Ingram et al. (2005) who found a strong inverse relationship between NDVI and stem density in a tropical secondary forest in Madagascar. In the aforementioned analysis a subset of extreme pixel values was used. Because of the inherent heterogeneity within each successional stage and the landscape as a whole for each structure and diversity 
characteristic in this study area however, it is important to use an inference technique that is not overly influenced by outliers.

We stress that forest structure and diversity analyses with remotely sensed data must focus on the canopy (i.e. the surface that is reflecting the radiation measured by the sensors) which in the dry season is a complex mixture of various contributors. It is inappropriate to assume however, that by using canopy reflectance reliable relationships can be established directly with subcanopy elements such as understory species richness, soil type or other structures or elements that are covered by a mature homogeneous canopy.

Maps such as the ones in Fig. 6 are a valuable resource for the management and conservation of this ecosystem, especially when considered in the context of being a comprehensive spatial snapshot of the forest structure and floristic diversity. Simple forest/non forest maps do not offer the detail necessary to assess forest degradation (Ingram et al., 2005) or recuperation. Therefore, on a regional scale, by illustrating the characteristics of the forest, areas can be more precisely assessed and prioritized for conservation than from only LAI or forest/non-forest maps. The changes in the characteristics of the forest (i.e. HCI, basal area, Shannon diversity, etc.) are the details needed to properly assess the condition of the forest within a specific area.

The analysis and interpretation of remotely sensed data as presented here in the form of structure and diversity components provide the opportunity to explore one of the most prevalent questions in forest regeneration: scale. As discussed by Webb et al. (1972), scale and thus the appearance of specific patterns or distributions in the landscape are a matter of perception driven by scale. The rapid analysis on a large scale of numerous structure and diversity variables over several years could lead to the discovery of the spatial dynamics of the Neotropical dry forest at numerous scales from the microscale plot level to an entire region. Furthermore expanding these analyses to include high spatial resolution airborne imagery (e.g. HyMap) could potentially improve the models. HyMap (Cocks et al., 1998) collects hyperspectral images with 128 bands from 400-2500 nm with a spectral bandwidth of 15-20 $\mathrm{nm}$.

Models incorporating high resolution hyperspectral data such as HyMap may further improve our understanding of the dynamics of secondary tropical dry forest regeneration. Analyzing changes in the structural and diversity components the distribution of individual species may be monitored to expand on observations such as the role of past anthropogenic disturbance along with random thinning, dispersal modes and colonization rates on the clumped distribution of Neotropical dry forest trees (Hubbell, 1979). Kalacska et al. (2004b) found that the pattern of species richness through the stages in Santa Rosa N.P. were partly consistent with Connell's (1978) ecological succession hypothesis. With the structure and diversity models constructed, long term remotely sensed monitoring of the area may reveal whether that pattern is consistent or whether the area follows a different trend over time. Stern et al. (2002) found that economically valuable species did not regenerate in disturbed areas of tropical dry forest whereas Kennard (2002) and Gould et al. (2002) reported the contrary. By including high spatial resolution hyperspectral imagery it would allow for expanding the scale of the studies by Castro-Esau et al. (2006), Zhang et al. (2006) and Clark et al. (2005) to map common (e.g. Rehdera trinervis, Guazuma ulmifolia, Semialarium mexicanum) and/or endangered and valuable (e.g. Guaiacum sanctum, Swietenia macrophylla, Platymiscium pleiostachyum) tree species from the tropical dry forest on a regional level and follow their patterns of regeneration (or lack thereof).

\section{Conclusions}

In this study we explored the use of Hyperion hyperspectral imagery from three seasons to estimate canopy biophysical parameters and floristic diversity. Data reduction/transformation and inference techniques were compared over the dry, wet and transition seasons and consequently we conclude the following:

The dry season image produced the optimal results for modeling. The dry season is also optimal for image acquisition (i.e. minimal cloud cover).

$\bigcirc$ A wavelet decomposition followed by stepwise regression to construct a model with only the most significant elements produced the best overall results following cross-validation.

$\bigcirc$ The subtle spectral features detected by the wavelet decomposition are optimal for estimating dry forest biophysical characteristics.

For future studies it is also important to quantitatively investigate the various contributors to the reflectance spectra in the dry season in this ecosystem to understand their respective importance in the various stages. In addition, the temporal change of the results, such as examining how an SVI changes for a given successional stage from the dry season to the wet season may improve the results of the models with the SVIs. The examination of this model in other dry and wet forest ecosystems would be important in order to investigate how the models change based on forest type (e.g. would neural networks produce better results in more homogeneous ecosystems?). In drier ecosystems such as Chamela in Mexico where apart from Riparian zones the entire forest is leafless in the dry season (regardless of successional stage), the forest structure poses different challenges in comparison to Santa Rosa (i.e. the structural variables do not follow the same trends for the successional stages) (Kalacska et al., 2005b). Wet forest ecosystems with denser canopies and less dramatic changes in leaf phenology and would possibly pose a different type of challenge because the differences in spectral reflectance based on general canopy characteristics (such as those examined here) may be even more subtle. The relative contribution of the different canopy elements would be substantially different in those contrasting ecosystems. The wavelength regions of greatest importance may therefore, help to understand the interactions and importance of the different canopy elements to the spectral response.

\section{Acknowledgements}

We thank our field assistants for their help in the data collection. We would also like to acknowledge Roger Blanco 
and Maria Marta Chavarría from the Santa Rosa National Park for their support and logistical assistance and Roberto Espinoza and Ulises Chavarría for their taxonomic identifications. This project was funded in part by the Inter-American Institute for Global Change, The Tinker Foundation through an Institutional Grant to the University of Alberta and the Canadian International Development Agency.

\section{References}

Arroyo-Mora, J. P., Sanchez-Azofeifa, G. A., Kalacska, M., Rivard, B., CalvoAlvarado, J. C., \& Janzen, D. (2005). Secondary forest detection in a Neotropical dry forest using Landsat 7 ETM+ and IKONOS imagery. Biotropica, 37, 497-507.

Asner, G. P. (1998). Biophysical and biochemical sources of variability in canopy reflectance. Remote Sensing of Environment, 64, 234-253.

Asner, G. P., Wessman, C. A., \& Schimel, D. S. (1998). Heterogeneity of savanna canopy structure and function from imaging spectrometry and inverse modeling. Ecological Applications, 8, 1022-1036.

Asner, G. P., Keller, M., Pereira, R., \& Zweede, J. C. (2002). Remote sensing of selective logging in Amazonia - Assessing limitations based on detailed field observations, Landsat ETM+, and textural analysis. Remote Sensing of Environment, 80, 483-496.

Asner, G. P., Keller, M., Pereira, R., Zweede, J. C., \& Silva, J. N. M. (2004). Canopy damage and recovery after selective logging in Amazonia: Field and satellite studies. Ecological Applications, 14, S280-S298 (Suppl. S).

Atzberger, C. (2004). Object-based retrieval of biophysical canopy variables using artificial neural nets and radiative transfer models. Remote Sensing of Environment, 93, 53-67.

Boddy, L., \& Morris, C. W. (1999). Artificial neural networks for pattern recognition. In A. H. Fielding (Ed.), Machine Learning Methods for Ecological Applications (pp. 37-88). Boston MA: Kluwer Academic Publishers.

Brondizio, E., Moran, E., Mausel, P., \& Wu, Y. (1996). Land cover in the Amazon Estuary: Linking of the Thematic Mapper with botanical and historical data. Photogrammetric Engineering and Remote Sensing, 62, 921-929.

Brown, S. (1997). Estimating biomass and biomass change of tropical forests: A primer. Rome: FAO (Forestry Paper no. 143).

Brown, S., \& Lugo, A. E. (1990). Tropical secondary forests. Journal of Tropical Ecology, 6, 1-32.

Bruce, L. M., Koger, C. H., \& Jiang, L. (2002). Dimensionality reduction of hyperspectral data using discrete wavelet transform feature extraction. IEEE Transactions on Geoscience and Remote Sensing, 40, 2331-2338.

Bruce, L. M, Morgan, C., \& Larsen, S. (1999). Automated detection of subpixel hyperspectral targets with continuous and discrete wavelets. IEEE Transactions on Geoscience and Remote Sensing, 37, 2217-2226.

Castro, K. L., Sanchez-Azofeifa, G. A., \& Rivard, B. (2003). Monitoring secondary tropical forests using space-borne data: implications for Central America. International Journal of Remote Sensing, 24, 1853-1894.

Castro-Esau, K., Sanchez-Azofeifa, G. A., \& Caelli, T. (2004). Discrimination of lianas and trees with leaf-level hyperspectral data. Remote Sensing of Environment, 90, 353-372.

Castro-Esau, K., Sanchez-Azofeifa, G. A., Rivard, B., Wright, S. J., \& Quesada, M. (2006). Variability in leaf optical properties of Mesoamerican trees and the potential for species classification. American Journal of Botany, 93, 517-530.

Chen, J. M. (1996). Evaluation of vegetation indices and a modified simple ratio for Boreal applications. Canadian Journal of Remote Sensing, 22, 229-241.

Clark, D. B., Read, J. M., Clark, M. L., Cruz, A. M., Dotti, M. F., \& Clark, D. A. (2004). Application of 1-M and 4-M resolution satellite data to ecological studies of tropical rain forests. Ecological Applications, 14, 61-74.

Clark, M. L., Roberts, D. A., \& Clark, D. B. (2005). Hyperspectral discrimination of tropical rain forest tree species at leaf to crown scales. Remote Sensing of Environment, 96, 375-398.

Cocks, T., Jenssen, R., Stewart, A., Wilson, I., \& Shields, T. (1998). The HyMap airborne hyperspectral sensor: The system, calibration and performance. First EARSeL Workshop on Imaging Spectroscopy Paris: EARSeL.

Connell, J. H. (1978). Diversity in tropical rain forests and coral reefs. Science, 199, 1302-1310.
Daily, G. C., Alexander, S., Erlich, P. R., Goulder, L., Lubchenko, J., Matson, P. A., et al. (1997). Ecosystem services: Benefits supplied to human societies by natural ecosytems. Issues in Ecology (pp. 1-16). Washington, DC: Ecological Society of America (number 2).

De Backer, S., Kempeneers, P., Debruyn, W., \& Scheunders, P. (2005). A band selection technique for spectral classification. IEEE Geoscience and Remote Sensing Letters, 2, 319-323.

de Carvalho, L. M. T., Acerbi Jr., F. W., Clevers, J. G. P. W., Fonseca, L. M. G., \& de Jong, S. M. (2004). Multiscale feature extraction from images using wavelets. In S. M. de Jong \& F. van der Meer (Eds.), Remote sensing image analysis including the spatial domain (pp. 237-270). Kluwer Academic Publishers.

FAO (2001). COFO-2000/INFS - Global forest resources assessment 2000. Rome: FAO of the United Nations.

Foody, G. M. (2003). Remote sensing of tropical forest environments: Towards the monitoring of environmental resources for sustainable development. International Journal of Remote Sensing, 24, 4035-4046.

Foody, G. M., \& Cutler, M. E. J. (2003). Tree biodiversity in protected and logged Bornean tropical rainforests and its measurement with satellite remote sensing. Journal of Biogeography, 10, 1053-1066.

Foody, G. M., Boyd, D. S., \& Cutler, M. E. J. (2003). Predictive relations of tropical forest biomass from Landsat TM data and their transferability between regions. Remote Sensing of Environment, 85, 463-474.

Foody, G. M., Palubinskas, G., Lucas, R. M., Curran, P. J., Honzak, M., \& Amaral, I. D. (1996). Identifying terrestrial carbon sinks: Classification of successional stages in regenerating tropical forest from Landsat TM data. Remote Sensing of Environment, 55, 205-216.

Fournier, R. A., Mailly, D., Walter, J. -M., \& Soudani, K. (2003). Measurement of forest structure. In M. Wulder S. Franklin (Eds.), Methods for remote sensing of forests: Concepts and case studies. New York: Kluwer.

Freeman, E. A., \& Ford, E. D. (2002). Effects of data quality on analysis of ecological pattern using the K(d) statistical function. Ecology, 83, 35-46.

Gitelson, A. A., Merzlyak, M. N., \& Chivkunova, O. (2001). Optical properties and non-destructive estimation of anthocyanin content in leaves. Journal of Photochemistry and Photobiology, 74, 38-45.

Gould, W. (2000). Remote sensing of vegetation, plant species richness and regional biodiversity hotspots. Ecological Applications, 10, 1861-1870.

Gould, K. A., Fredricksen, T. S., Morales, F., Kennard, D., Putz, F. E., Mostacedo, B., et al. (2002). Post-fire tree regeneration in lowland Bolivia: Implications for fire management. Forest Ecology and Management, 165, $225-245$.

Greenberg, J. A., Dobrowski, S. Z., \& Ustin, S. L. (2005a). Shadow allometry: Estimating tree structural parameters using hyperspatial image analysis. Remote Sensing of Environment, 97, 15-25.

Greenberg, J. A., Kefauver, S. C., Stimson, H. C., Yeaton, C. J., \& Ustin, S. L. (2005b). Survival analysis of a neotropical rainforest using multitemporal satellite imagery. Remote Sensing of Environment, 96, 202-211.

Holdridge, L. R. (1967). Life zone ecology. San Jose, Costa Rica: Tropical Science Center.

Huang, R., \& He, M. (2005). Band selection based on feature weighting for classification of hyperspectral data. IEEE Geoscience and Remote Sensing Letters, 2, 156-159.

Hubbell, S. P. (1979). Tree dispersion, abundance, and diversity in a tropical dry forest. Science, 203, 1299-1309.

Ingram, J. C., Dawson, T. P., \& Whittaker, R. J. (2005). Mapping tropical forest structure in Southeastern Madagascar using remote sensing and artificial neural networks. Remote Sensing of Environment, 94, 491-507.

Isaaks, E. H., \& Srivastava, R. M. (1989). Applied geostatistics. Oxford: Oxford University Press.

Jacquemoud, S., Ustin, S. L., Verdebout, J., Schmuck, G., Andreoli, G., \& Hosgood, B. (1996). Estimating leaf biochemistry using the PROSPECT leaf optical properties model. Remote Sensing of Environment, 56, 194-202.

Janzen, D. H. (1988a). Guanacaste National Park: Tropical ecological and biocultural restoration. In J. J. Cairns (Ed.), Rehabilitating damaged ecosystems, Vol. II (pp. 143-192). Boca Raton, Florida: CRC Press.

Janzen, D. H. (1988b). Management of habit fragments in a tropical dry forest: Growth. Annals of the Missouri Botanical Garden, 75, 105-116. 
Janzen, D. H. (2000). Costa Rica's Area de Conservacion Guanacaste: A long march to survival through non-damaging biodevelopment. Biodiversity, 1, 7-20.

Janzen, D. H. (1986). Tropical dry forests: the most endangered major tropical ecosystem. In E. O. Wilson (Ed.), Biodiversity (pp. 130-137). Washington DC: National Academy Press.

Kalacska, M., Calvo-Alvarado, J. C., \& Sanchez-Azofeifa, G. A. (2005a). Calibration and assessment of seasonal changes in leaf area index of a tropical dry forest in different stages of succession. Tree Physiology, 25, 733-744.

Kalacska, M., Sanchez-Azofeifa, G. A., Calvo-Alvarado, J. C., Rivard, B., \& Quesada, M. (2005b). Effects of season and successional stage on leaf area index and spectral vegetation indices in three Mesoamerican tropical dry forests. Biotropica, 37, 486-496.

Kalacska, M., Sanchez-Azofeifa, G. A., Rivard, B., Calvo-Alvarado, J. C., Journet, A. R. P., Arroyo-Mora, J. P., et al. (2004a). Leaf area index measurements in a tropical moist forest: A case study from Costa Rica. Remote Sensing of Environment, 91, 134-152.

Kalacska, M., Sanchez-Azofeifa, G. A., Calvo-Alvarado, J. C., Rivard, B., Quesada, M., \& Janzen, D. H. (2004b). Species composition, similarity and diversity in three successional stages of tropical dry forest. Forest Ecology and Management, 200, 227-247.

Kennard, D. K. (2002). Secondary forest succession in a tropical dry forest: Patterns of development across a 50-year chronosequence in lowland Bolivia. Journal of Tropical Ecology, 18, 53-66.

Kerr, J. T., \& Deguise, I. (2004). Habitat loss and the limits to endangered species. Ecology Letters, 7, 1163-1169.

Khurshid, K. S., Staenz, K., Sun, L., Neville, R., White, H. P., Bannari, A., et al. (2006). Preprocessing of EO-1 Hyperion data. Canadian Journal of Remote Sensing, 32, 84-97.

Lacaze, B., \& Joffre, R. (1994). Exracting biochemical information from visible and near infrared reflectance spectroscopy of fresh and dried leaves. Journal of Plant Physiology, 144, 277-281.

Lee, K. S., Cohen, W. B., Kennedy, R. E., Maiersperger, T. K., \& Gower, S. T. (2004). Hyperspectral versus multispectral data for estimating leaf area index in four different biomes. Remote Sensing of Environment, 91, 508-520.

Li, J., Bruce, L. M., Byrd, J., \& Barnett, J. (July 9-13, 2001). Automated detection of pueraria Montanta (Kudzu) through Haar analysis of hyperspectral reflectance data. IEEE International Geosciences and Remote Sensing Symposium (Sydney Australia).

Lucas, R. M., Honzak, M., Curran, P. J., Foody, G. M., Milne, R., Brown, T., et al. (2000). Mapping the regional extent of tropical forest regeneration stages in the Brazilian Legal Amazon using NOAA AVHRR data. International Journal of Remote Sensing, 21, 2855-2881.

Magurran, A. E. (2004). Measuring biological diversity. Malden MA: Blackwell Science.

Mallat, S. G. (1989). A theory for multiresolution signal decomposition: The wavelet representation. IEEE Transactions on Pattern Analysis and Machine Intelligence, 11, 647-693.

Mausel, P., Wu, Y., Li, Y., Moran, E. F., \& Brondizio, E. S. (1993). Spectral identification of successional stages following deforestation in the Amazon. Geocarto International, 4, 61-71.

Menon, W., \& Bawa, K. S. (1997). Applications of geographic information systems, remote-sensing, and a landscape ecology approach to biodiversity conservation in the Western Ghats. Current Science, 73(2), 134-145.

Merzlyak, M. N., \& Chivkunova, O. (2000). Light-stress induced pigment changes and evidence for anthocyanin photoprotection in apple fruit. Journal of Photochemistry and Photobiology, 55, 154-162.

Misiti, M., Misiti, Y., Oppenheim, G., \& Poggi, J. M. (1996). Wavelet Toolbox User's Guide Natick MA. The Mathworks Inc.

Mooney, H. A., Bullock, S. H., \& Medina, E. (1995). Introduction. In S. H. Bullock, H. A. Mooney, \& E. Medina (Eds.), Seasonally dry tropical forests (pp. 1-8). Cambridge University Press.

Murphy, P. G., \& Lugo, A. E. (1986). Structure and biomass of a subtropical dry forest in Puerto Rico. Biotropica, 18, 89-96.

Nagendra, H. (2001). Using remote sensing to assess biodiveristy. International Journal of Remote Sensing, 22, 377-400.

Nagendra, H., \& Gadgil, M. (1999a). Biodiversity assessment at multiple scales: linking remotely sensed data with field information. Proceedings of the National Academy of Sciences of the United States of America, 96, 9154-9158

Nagendra, H., \& Gadgil, M. (1999b). Satellite imagery as a tool for monitoring species diversity: An assessment. Journal of Applied Ecology, 36, 388-397.

Neville, R. A., Sun, L., \& Staenz, K. (2003). Detection of spectral line curvature in imaging spectrometer data. In S. Shen, \& P. Lewis (Eds.), SPIE Algorithms and Technologies for Multispectral Hyperspectral and Ultraspectral Imagery IX, Vol. 5093. (pp. 144-154)(pp. 144-154).

Penuelas, J., \& Filella, I. (1998). Visible and near-infrared reflectance techniques for diagnosing plant physiological status. Trends in Plant Science, 3, 151-156.

Pfaff, A. S. P., \& Sanchez-Azofeifa, G. A. (2004). Deforestation pressure and biological reserve planning: a conceptual approach and an illustrative application for Costa Rica. Resource and Energy Economics, 26, 237-254.

Pfaff, A. S. P., Kerr, S., Hughes, R. F., Liu, S., Sanchez-Azofeifa, G. A., Schimel, D., et al. (2000). The Kyoto protocol and payments for tropical forests: An interdisciplinary method for estimating carbon-offset supply and increasing the feasibility of a carbon market under the CDM. Ecological Economics, 35, 203-221.

$\mathrm{Pu}, \mathrm{R} .$, \& Gong, P. (2004). Wavelet transform applied to EO-1 hyperspectral data for forest LAI and crown closure mapping. Remote Sensing of Environment, 91, 212-224

Quesada, M., \& Stoner, K. E. (2004). Threats to the conservation of the tropical dry forest in Costa Rica. In G. W. Frankie, A. Mata, \& S. B. Vinson (Eds.), Biodiversity conservation in Costa Rica: Learning the lessons in a seasonally dry forest (pp. 266-280). Berkely, CA: University of California Press.

Ripley, D. (1976). The second-order analysis of stationary point processes. Journal of Applied Probability, 13, 255-266.

Roberts, D., Ustin, S. L., Ogunjemiyo, S., Greenberg, J., Dobrowski, S. Z., Chen, J., et al. (2004). Spectral and structural measures of Northwest forest vegetation and leaf and landscape scales. Ecosystems, 7, 545-562.

Ross, J. K. (1981). The radiation regime and architecture of plant stands. Boston: Kluwer.

Ruiz, J., Fandiño, M. C., \& Chazdon, R. L. (2005). Vegetation structure, composition, and species richness across a 56-year chronosequence of dry tropical forest on Providencia Island, Colombia. Biotropica, 37, 520-530.

Running, S. W., Peterson, D. L., Spanner, M. A., \& Teuber, K. B. (1986). Remote sensing of coniferous forest leaf area. Ecology, 67, 273-276.

Russell, S., \& Norvig, P. (2003). Learning from observation. In S. Russell \& P. Norvig (Eds.), Artificial Intelligence A Modern Approach (pp. 649-677). New Jersey: Prentice-Hall.

Sanchez-Azofeifa, G. A., Daily, G. C., Pfaff, A. S. P., \& Busch, C. (2003). Integrity and isolation of Costa Rica's national parks and biological reserves: examining the dynamics of land-cover change. Biological Conservation, 109, 123-135.

Sanchez-Azofeifa, G. A., Harriss, R. C., \& Skole, D. L. (2001). Deforestation in Costa Rica: A quantitative analysis using remote sensing imagery. Biotropica, 33, 378-384.

Sánchez-Azofeifa, G. A., Quesada, M., Rodríguez, J. P., Nassar, M., Stoner, K. E., Castillo, A., et al. (2005). Research priorities for Neotropical dry forests. Biotropica, 37, 477-485.

Schlerf, M., Atzberger, C., \& Hill, J. (2005). Remote sensing of forest biophysical variables using HyMap imaging spectrometer data. Remote Sensing of Environment, 95, 177-194.

Sims, D. A., \& Gamon, J. A. (2002). Relationships between leaf pigment content and spectral reflectance across a wide range of species, leaf structure and developmental stages. Remote Sensing of Environment, 81, 337-354.

Sims, D. A., \& Gamon, J. A. (2003). Estimation of vegetation water content and photosynthetic tissue area from spectral reflectance: A comparison of indices based on liquid water and chlorophyll absorption features. Remote Sensing of Environment, 84, 526-537.

Staenz, K., Szeredi, T., \& Schwarz, J. (1998). ISDAS - A system for processing/analyzing hyperspectral data. Canadian Journal of Remote Sensing, 24, 99-133.

Steininger, M. K. (1996). Tropical secondary forest regrowth in the Amazon: Age, area and change estimation with Thematic data. International Journal of Remote Sensing, 20, 839-877. 
Steininger, M. K. (2000). Satellite estimation of tropical secondary forest above-ground biomass: Data from Brazil and Bolivia. International Journal of Remote Sensing, 21, 1139-1157.

Stern, M., Quesada, M., \& Stoner, K. E. (2002). Changes in composition and structure of a tropical dry forest following intermittent cattle grazing. Revista de Biologia Tropical, 50, 1021-1034.

Stoner, E. R., \& Baumgardner, M. F. (1981). Characteristic variation in reflectance on surface soils. Soil Science Society of America Journal, 45, 1161-1165.

Sun, L., Neville, R., Staenz, K., White, H. P. submitted for publication. Automatic destriping of Hyperion imagery based on spectral moment mapping. Canadian Journal of Remote Sensing.

Thenkabail, P. S., Nolte, C., \& Lyon, J. G. (2004). Remote sensing and GIS modeling for selection of a benchmark research area in the inland valley agroecosystems of West and Central Africa. Photogrammetric Engineering and Remote Sensing, 66, 755-768.

Townshend, J., Justice, C., Li, W., Gurney, C., \& McManus, J. (1991). Global land cover classification by remote sensing - Present capabilities and future possibilities. Remote Sensing of Environment, 35, 243-255.

Tuner, D. P., Cohen, W. B., Kennedy, R. E., Fassnacht, K. S., \& Briggs, J. M. (1999). Relationships between leaf area index and Landsat TM spectral vegetation indices across three temperate zone sites. Remote Sensing of Environment, 70, 52-68.

Tuomisto, H., Poulsen, A. D., Ruokolainen, K., Moran, R. C., Quintana, C., Celi, J., et al. (2003). Linking floristic patterns with soil heterogeneity and satellite imagery in Ecuadorian Amazonia. Ecological Applications, 13, 352-371.

Turner, W., Sepctor, S., Gardiner, N., Fladeland, M., Sterling, E., \& Steininger, M. (2003). Remote sensing for biodiversity science and conservation. Trends in Ecology and Evolution, 18, 306-314. van der Meer, F. (1999). Physical principles of optical remote sensing. In A Stein, F. van der Meer, \& B. Gorte (Eds.), Spatial statistics for remote sensing (pp. 27-40). Boston: Kluwer Academic Publishers.

Wasserman, P. E. (1993). Advanced methods in neural computing (pp. 155-161). New York: Van Nostrand Reinhold.

Webb, L. J., Tracey, J. G., \& Williams, W. T. (1972). Regeneration and pattern in the subtropical rain forest. Journal of Ecology, 60, 675-695.

Wessman, C., Aber, J. D., Peterson, D. L., \& Melillo, J. M. (1988). Remote sensing of canopy chemistry and nitrogen cycling in temperate forest ecosystems. Nature, 335, 154-156.

White, H. P., Khurshid, K. S., Hitchock, R., Neville, R., Sun, L., Champagne, C. M., et al. (2004). From at-sensor observation to at-surface reflectance Calibration steps for Earth Observation hyperspectral sensors. IGARSS Proc (pp. 3241-3244).

White, H. P., Miller, J. R., \& Chen, J. M. (2001). Four-scale linear model for anisotropic reflectance (FLAIR) for plant canopies - Part I: Model description and partial validation. IEEE Transactions on Geoscience and Remote Sensing, 39, 1072-1083.

White, H. P., Miller, J. R., \& Chen, J. M. (2002). Four-scale linear model for anisotropic reflectance (FLAIR) for plant canopies — Part II: Validation and inversion with CASI, POLDER, and PARABOLA data at BOREAS. IEEE Transactions on Geoscience and Remote Sensing, 40, 1038-1046.

Zhang J., Rivard B., Sanchez-Azofeifa G. A. (in press). Intra and inter-class spectral variability of tropical tree species at La Selva, Costa Rica: Implications for species identification using HYDICE imagery. Remote Sensing of Environment. 